\title{
ALK Positive Anaplastic Large Cell Lymphoma of Oral Cavity: A Case Report
}

\author{
Fatemeh Nili (iD ${ }^{1}$, Vahid Soleimani ${ }^{1}$, Niusha Nobari ${ }^{1}$, Hana Saffar ${ }^{1}$ and Arghavan Etebarian (iD ${ }^{2,{ }^{*}}$ \\ ${ }^{1}$ Pathology Department, Cancer Institute, Imam Khomeini Hospital Complex, Tehran University of Medical Sciences, Tehran, Iran \\ ${ }^{2}$ Department of Oral and Maxillofacial Pathology, School of Dentistry, Alborz University of Medical Sciences, Karaj, Iran \\ "Corresponding author: Department of Oral and Maxillofacial Pathology, School of Dentistry, Alborz University of Medical Sciences, Karaj, Iran. Email: \\ arghavan.etebarian@gmail.com
}

Received 2018 October 25; Revised 2019 January 14; Accepted 2019 January 15.

\begin{abstract}
Introduction: Anaplastic lymphoma kinase-positive (ALK+) anaplastic large cell lymphoma is a rare subtype of non-Hodgkin lymphomas, which is usually presented as a systemic advanced stage disease. Extranodal involvement is common in skin, bone, soft tissue, lung and liver. Primary presentation in oral cavity is extremely rare.

Case Presentation: Here, a 28-year-old man with gingival swelling in the left mandibular molar area after tooth extraction and regional lymphadenopathy is reported. Microscopic examination revealed anaplastic large lymphoid cells with the positive expression of ALK protein.

Conclusions: Although the overall survival of ALK-positive anaplastic large cell lymphoma is better than other types of T-cell lymphomas, it is not clear for its oral counterparts.
\end{abstract}

Keywords: Anaplastic Lymphoma Kinase-Positive, Anaplastic Large Cell Lymphoma, Oral Cavity

\section{Introduction}

Anaplastic large cell lymphoma (ALCL) is a subgroup of peripheral T-cell lymphoma, a distinct clinicopathological entity with the highly aggressive clinical course (1). It is usually identified by large neoplastic cells with abundant cytoplasm and marked nuclear pleomorphism, expressing CD30 molecule (previously named Ki-1) (2). ALCLs are further categorized into two groups according to their clinical and immunohistochemical features: (1) CD30 + T-cell lymphoproliferative disorders (primary cutaneous ALCL and lymphomatoid papulosis), and (2) primary systemic ALCL (ALK+ and ALK-negative) $(3,4)$. ALK is a receptor kinase inhibitor that plays an essential role in the development of neural tissue in the early stages of development (5). In addition to its physiologic expression, ALK can be oncogenically altered into several malignancies including non-small cell lung cancer, ALCL, inflammatory myofibroblastic tumors, neuroblastoma, and others $(6,7)$. The expression of ALK in ALCL occurs secondary to one of the several chromosol aberrations that involve the ALK gene on chromosome 2p23. Translocation $\mathrm{t}(2 ; 5)(\mathrm{p} 23 ; \mathrm{q} 35)$ is the most common of these aberrations occuring in $85 \%$ of ALK $+\operatorname{ALCL}$ cases $(5,8)$ and involving the nucleophosmin (NPM) gene, which induces the formation of the oncogenic tyrosine kinase NPM-ALK (9).

ALK + ALCL affects children and young adults and has a striking male predominance, especially in the first 3 decades of life (1). It accounts for about $5 \%$ of all nonHodgkin lymphomas, $50 \%$ to $60 \%$ of ALCL (10) and $10 \%$ to $15 \%$ of children's non-Hodgkin lymphomas (11). ALK + ALCL patients respond well to chemotherapy with a good prognosis, whereas the ALK-ALCLs occur mostly in elderly patients (50 - 70 years) with unpredictable clinical behavior (3). Although peripheral lymphadenopathy is the most common clinical presentation in patients with ALK + ALCLs, extra-nodal involvements of the skin, bone, lung, liver, gastrointestinal tract (GI), and central nervous system (CNS) can also occur (2). Involvement of oral cavity is extremely rare such that, for instance, fewer than 15 cases of ALCL presenting primarily in the oral cavity have been reported in the English literature so far (12-17). Here, we report a rare case of localized ALK + ALCL presented as a gingival mass in a 28-year-old man. We also discuss the latest findings in this regard according to the related literature. 


\section{Case Presentation}

A 28-year-old male patient was referred to our dental clinic with the complaint of prolonged pain, discomfort on swallowing and left mandibular area swelling 5 weeks after extraction of the second molar. The physical examination revealed a gingival mass with hemorrhagic surface and a firm palpable mass in the submandibular region with cervical lymphadenopathy. Sonography of the head and neck area indicated 4 heterogeneous and hypoechoic lesions measuring 11 to $26 \mathrm{~mm}$ in the left submandibular and submental areas. Moreover, oval-shaped lymph nodes with prominent hilum in the left jugular region were detected. Ill-defined lytic lesions of the posterior left mandibular body along with enlarged lymph nodes measuring up to 20 $\mathrm{mm}$ in the left submental and submandibular areas were shown by multi-slice spiral computed tomography with 3dimensional reconstruction (Figure $1 \mathrm{~A}$ and $\mathrm{B}$ ).

An excisional biopsy of the gingival mass revealed a diffuse and monotonous proliferation of discohesive pleomorphic large atypical cells with hyperchromatic nuclei and scattered horse-shoe or kidney-shaped figures containing one or two prominent nucleoli and voluminous cytoplasm (hallmark cells). Plentiful mitoses, foci of necrosis, and hemorrhage were also identified (Figure 1C and D). Immunohistochemistry studies showed positivity for Lymphocyte common antigen (LCA), CD3, CD30, ALK, and Ki-67 (70\% - 80\%) in the tumoral cells (Figure 2A - D). Neoplastic cells were negative for CD4, CD8, CD20, TdT, CD34, CD56, CD68, BCL2 (B-cell lymphoma 2), and S100. According to the morphology and immunohistochemistry study results, diagnosis of ALK + ALCL was considered for this patient. Also, routine hemogram analysis revealed severe leukocytosis (WBC: $30000 / \mathrm{mm}^{3}$ ); therefore, bone marrow biopsy, aspiration, and flow cytometry were done, which disclosed only $2 \%$ blasts and $85 \%$ mature myeloid cells. More investigations for existence of viral infection including HTLV1 (Human T-lymphotropic virus), HTLV-2, HBV (Hepatitis B virus), HCV (Hepatitis C virus), and HIV (Human immunodeficiency virus) were negative. The patient immediately underwent chemotherapy according to the "international protocol of anaplastic large cell lymphoma" with CHOEP (cyclophosphamide, doxorubicin, etoposide, vincristine and prednisone). Three months after chemotherapy, a complete remission of clinical signs was achieved. After 25 months of extensive follow-up, the patient is now alive and in a good condition with no sign of recurrence or relapse of the disease.

\section{Discussion}

In 1985, Stein et al. identified a unique large cell lymphoma with anaplastic cytology, an unusual sinus growth pattern, and strong expression of the antigen Ki-1 (18). Subsequently, Ki-1 was identified as an activation antigen (CD30) and a member of the tumor necrosis factor receptor family, which could be presented on T-cells, B-cells, and even activated histiocytes (19). The Revised EuropeanAmerican Lymphoma (REAL) classification used the current nomenclature of ALCL with restriction to tumors with T-cell or null-cell phenotype (19). Later on, association with $t(2 ; 5)$ was discovered in 1989 and cloning of the ALK gene was performed in 1994 (2). Although ALK+ and ALK-ALCLs were part of the same category in the third edition of World Health Organization (WHO) classification, they are considered as distinct entities at molecular and genetic level with improved criteria for their recognition in the latest version (20).

ALK + ALCL is a localized or systemic advanced stage disease (8). Lymph node involvement and systemic B-type symptoms including high fever, night sweats, and weight loss are the most common clinical presentations in about $70 \%$ to $75 \%$ of the patients (9). Extra-nodal involvement with or without lymphadenopathy is also frequent, especially in the skin, bone, soft tissue, and lung (2). CNS, GI, and mediastinum are rarely involved and account for less than $5 \%$ of the patients (1). Malignant lymphomas constitute $2 \%$ to $5 \%$ of all oral malignancies (14). About $98 \%$ of the cases of oral non-Hodgkin lymphomas reviewed by Kemps and coworkers were of B cell lineage, and most of them were of diffuse large B cell type (15). A few cases of ALCL with oral involvement have been reported in the English-language literature (12-17). Palatal mucosa, gingiva, tongue, lips, buccal mucosa, and the floor of the mouth are the most common sites of involvement in the oral cavity (17).

ALK + ALCL has a broad morphologic spectrum, but contains a varying proportion of hallmark cells with eccentric, horseshoe- or kidney-shaped nuclei often with one, or more prominent nucleoli in almost all cases (2). There are several histomorphological variants of ALCL, including common type, monomorphic variant, lymphohistiocytic variant, small cell variant, mixed cell variant, giant cell variant, and sarcomatoid subtype. Loss of expression of multiple T-lineage markers and disturbed appearance of the TCR-CD3 complex can also be recognized. CD30 is positive in almost all of the neoplastic cells, showing pleomorphism with abundant cytoplasm and cohesive growth. 

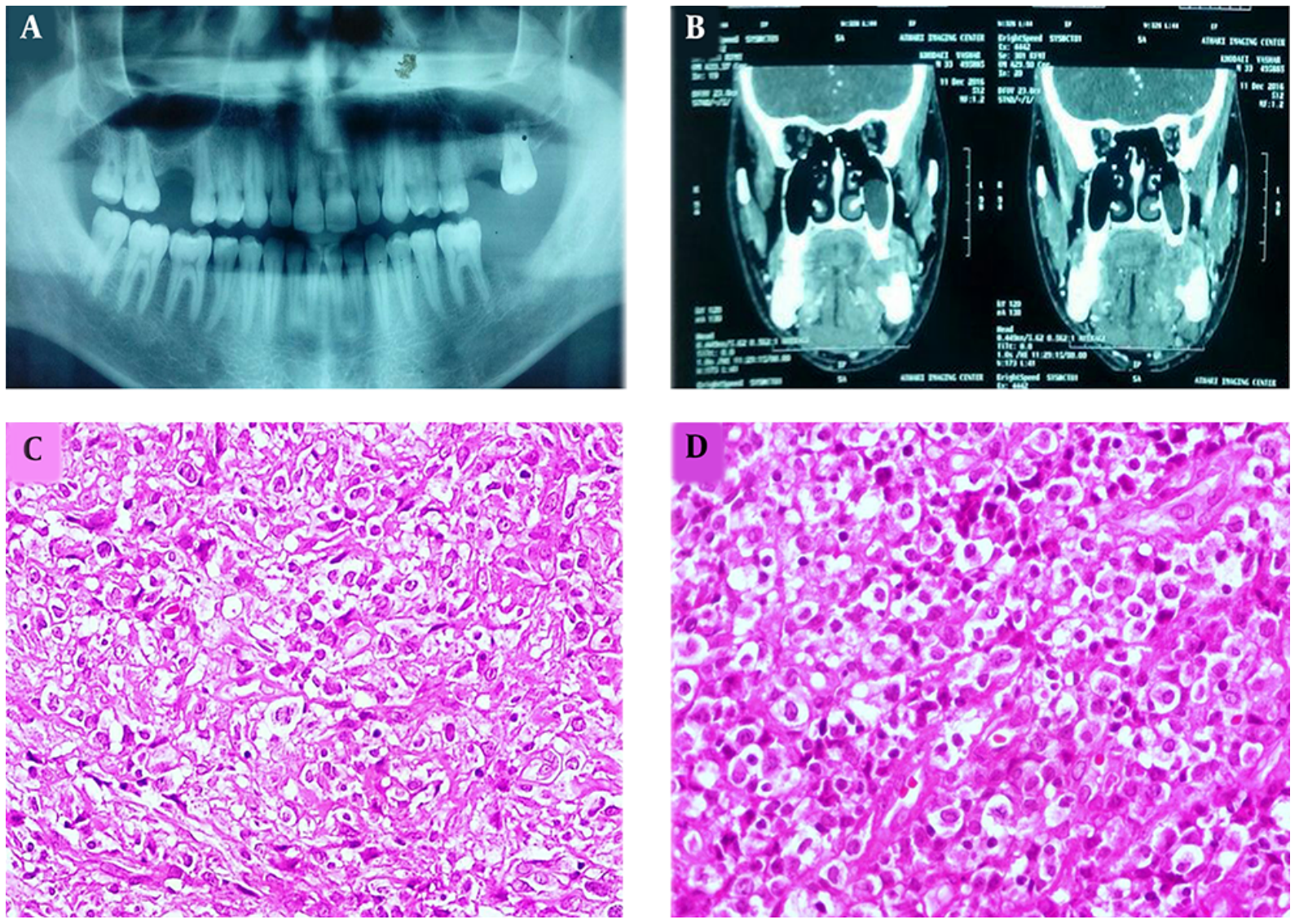

Figure 1. Panoramic view of the patient with extracted left second mandibular molar in the area of gingival mass (A). CT scan revealed ill-defined lytic lesions of the posterior left mandibular. Body along with enlarged lymph nodes measuring up to $20 \mathrm{~mm}$ in the left submental and submandibular areas (B). Proliferation of discohesive pleomorphic large atypical cells with hyperchromatic nuclei and scattered horse-shoe or kidney-shaped figures containing one or more prominent nucleoli and voluminous cytoplasm (H\&E staining, $400 \times, C$ and D).

The accurate diagnosis of ALCL has important clinical implications due to the highly treatable form of lymphomas, mostly with polychemotherapy, and sometimes, through bone marrow transplant. ALK-rearranged tumors represent a specific subset of tumors that can also be effectively targeted with currently available ALK inhibitors, and testing for these molecular aberrations is now an obligatory part of the diagnosis $(6,21)$. In a recent study by Gambacorti Passerini et al., approximately half of the ALK + ALCL patients, who achieve complete remission by Crizotinib, stay disease-free for prolonged periods (22). Although most of these patients present with advanced-stage (III - IV) disease, they have a remarkably better prognosis than the patients with ALK-ALCL or other types of T-cell lymphomas according to the international prognostic index (23). Nevertheless, some patients do present with high-risk disease and sub-optimal remis- sions (2). Complete remission can often be achieved by multi-agent chemotherapy, and excellent outcomes have been reported for ALCL occurring in pediatrics and adults treated with a variety of Anthracycline-based chemotherapy regimens including CHOP (Cyclophosphamide, Doxorubicin, Vincristine, Prednisone), CHOEP (CHOP plus Etoposide) or MACOP-B (Methotrexate, Doxorubicin, Cyclophosphamide, Vincristine, Prednisone, Bleomycin) (2). ALK protein expression has been proposed as an independent predictor for survival in ALCL patients $(1,2)$. Age, Ann Arbor stage, bulky disease, lactate dehydrogenase level, histology, bone marrow, and extra-nodal involvement are other main prognostic indicators for patients with ALCL $(24,25)$. The overall 5-year survival is about 705 to $80 \%$. Despite a $30 \%$ rate of recurrence, these tumors often remain sensitive to chemotherapy (2).

As shown in the present case, it is essential to consider 

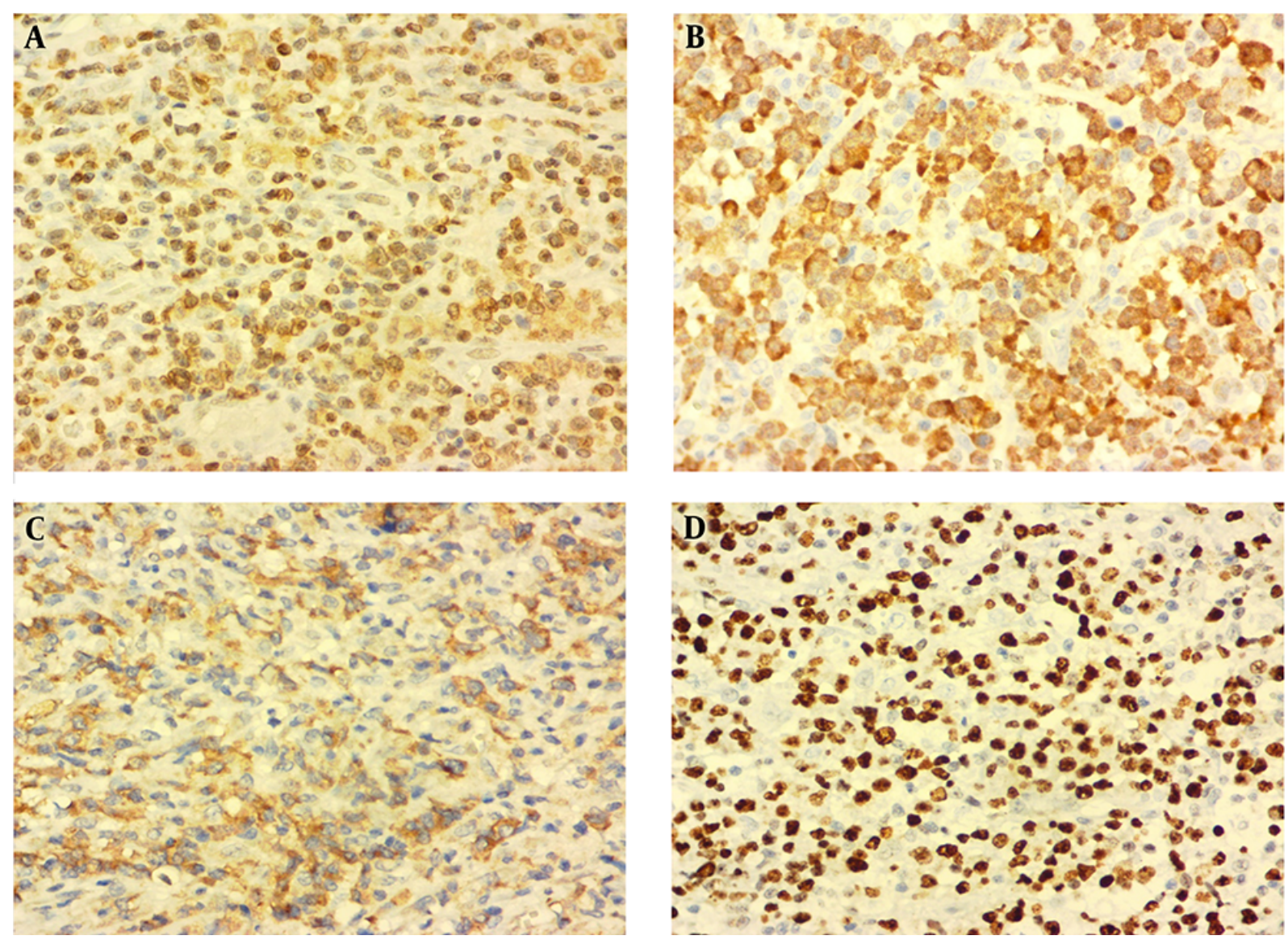

Figure 2. The positive expression of CD3 (A), CD30 (B), ALK (C), and Ki67 (D) in tumor cells (IHC staining, 400 $\times$ )

malignant lymphoma, including ALCL in a differential diagnosis for the patients with a gingival mass, and dentists can play a crucial role in its early detection. To establish a definite diagnosis, microscopic evaluation and immunohistochemical staining are mandatory. The new development of novel therapies targeting CD30 and ALK is significant and promising treatment advances for ALCL patients that can improve their survival $(8,9,21,22)$.

\section{Acknowledgments}

None declared.

\section{Footnotes}

Authors' Contribution: None declared.

Conflict of Interests: The authors have no conflict of interest to be disclosed.

Funding/Support: None declared.
Financial Disclosure: None declared.

Patient Consent: Written informed consent was obtained from the patient for publication of this case report and accompanying images.

\section{References}

1. Falini B, Pileri S, Zinzani PL, Carbone A, Zagonel V, Wolf-Peeters C, et al. ALK+ lymphoma: Clinico-pathological findings and outcome. Blood. 1999;93(8):2697-706. [PubMed: 10194450].

2. Ferreri AJ, Govi S, Pileri SA, Savage KJ. Anaplastic large cell lymphoma, ALK-positive. Crit Rev Oncol Hematol. 2012;83(2):293-302. doi: 10.1016/j.critrevonc.2012.02.005. [PubMed: 22440390].

3. Stein H, Foss HD, Durkop H, Marafioti T, Delsol G, Pulford K, et al. $\mathrm{CD} 30(+)$ anaplastic large cell lymphoma: A review of its histopathologic, genetic, and clinical features. Blood. 2000;96(12):3681-95. [PubMed: 11090048].

4. ten Berge RL, Oudejans JJ, Ossenkoppele GJ, Meijer CJ. ALK-negative systemic anaplastic large cell lymphoma: Differential diagnostic and prognostic aspects-a review. J Pathol. 2003;200(1):4-15. doi: 10.1002/path.1331. [PubMed: 12692835]. 
5. Morris SW, Kirstein MN, Valentine MB, Dittmer KG, Shapiro DN, Saltman DL, et al. Fusion of a kinase gene, ALK, to a nucleolar protein gene, NPM, in non-Hodgkin's lymphoma. Science. 1994;263(5151):1281-4. doi: 10.1126/science.8122112. [PubMed: 8122112].

6. Holla VR, Elamin YY, Bailey AM, Johnson AM, Litzenburger BC, Khotskaya YB, et al. ALK: A tyrosine kinase target for cancer therapy. Cold Spring Harb Mol Case Stud. 2017;3(1). a001115. doi: 10.1101/mcs.a001115. [PubMed: 28050598]. [PubMed Central: PMC5171696].

7. Mologni L. Current and future treatment of anaplastic lymphoma kinase-rearranged cancer. World J Clin Oncol. 2015;6(5):104-8. doi: 10.5306/wjco.v6.i5.104. [PubMed: 26468446]. [PubMed Central: PMC4600184].

8. Amin HM, Lai R. Pathobiology of ALK+ anaplastic large-cell lymphoma. Blood. 2007;110(7):2259-67. doi: 10.1182/blood-2007-04060715. [PubMed: 17519389]. [PubMed Central: PMC1988960].

9. George SK, Vishwamitra D, Manshouri R, Shi P, Amin HM. The ALK inhibitor ASP3026 eradicates NPM-ALK(+) T-cell anaplastic large-cell lymphoma in vitro and in a systemic xenograft lymphoma model. Oncotarget. 2014;5(14):5750-63. doi: 10.18632/oncotarget.2170. [PubMed: 25026277]. [PubMed Central: PMC4170597].

10. Kadin ME, Morris SW. The $\mathrm{t}(2 ; 5)$ in human lymphomas. Leuk Lymphoma. 1998;29(3-4):249-56. doi: 10.3109/10428199809068562. [PubMed: 9684923].

11. Burkhardt B, Zimmermann M, Oschlies I, Niggli F, Mann G, Parwaresch $\mathrm{R}$, et al. The impact of age and gender on biology, clinical features and treatment outcome of non-Hodgkin lymphoma in childhood and adolescence. Br J Haematol. 2005;131(1):39-49. doi: 10.1111/j.1365-2141.2005.05735.x. [PubMed: 16173961].

12. Narwal A, Yadav AB, Prakash S, Gupta S. Anaplastic lymphoma kinase negative anaplastic large cell lymphoma of hard palate as first clinical manifestation of acquired immune deficiency syndrome. Contemp Clin Dent. 2016;7(1):114-7. doi: 10.4103/0976-237X.177115. [PubMed: 27041916]. [PubMed Central: PMC4792042].

13. Matsumoto N, Ohki H, Mukae S, Amano Y, Harada D, Nishimura $S$, et al. Anaplastic large cell lymphoma in gingiva: Case report and literature review. Oral Surg Oral Med Oral Pathol Oral Radiol Endod. 2008;106(4):e29-34. doi: 10.1016/j.tripleo.2008.05.037. [PubMed: 18656392].

14. Savarrio L, Gibson J, Dunlop DJ, O'Rourke N, Fitzsimons EJ. Spontaneous regression of an anaplastic large cell lymphoma in the oral cavity: First reported case and review of the literature. Oral Oncol. 1999;35(6):609-13. doi: 10.1016/S1368-8375(99)00034-2. [PubMed: 10705098].

15. Kemp S, Gallagher G, Kabani S, Noonan V, O'Hara C. Oral nonHodgkin's lymphoma: Review of the literature and World Health Organization classification with reference to 40 cases. Oral Surg Oral Med Oral Pathol Oral Radiol Endod. 2008;105(2):194-201. doi: 10.1016/j.tripleo.2007.02.019. [PubMed: 17604660].

16. Notani KI, Shindoh M, Takami T, Yamazaki Y, Kohgo T, Fukuda H. Anaplastic large cell lymphoma (ALCL) in the oral mucosa with repeating recurrence and spontaneous regression of ulceration: report of a case. Oral Med Pathol. 2002;7(2):79-82. doi: 10.3353/omp.7.79.

17. Epstein JB, Epstein JD, Le ND, Gorsky M. Characteristics of oral and paraoral malignant lymphoma: A population-based review of 361 cases. Oral Surg Oral Med Oral Pathol Oral Radiol Endod. 2001;92(5):51925. doi: 10.1067/moe.2001.116062. [PubMed:11709688].

18. Stein H, Mason DY, Gerdes J, O'Connor N, Wainscoat J, Pallesen G, et al. The expression of the Hodgkin's disease associated antigen Ki-1 in reactive and neoplastic lymphoid tissue: evidence that Reed-Sternberg cells and histiocytic malignancies are derived from activated lymphoid cells. Blood. 1985;66(4):848-58. [PubMed: 3876124].

19. Andreesen R, Brugger W, Lohr GW, Bross KJ. Human macrophages can express the Hodgkin's cell-associated antigen Ki-1 (CD30). Am J Pathol. 1989;134(1):187-92. [PubMed: 2536522]. [PubMed Central: PMC1879544].

20. Swerdlow SH, Campo E, Pileri SA, Harris NL, Stein H, Siebert R, et al. The 2016 revision of the World Health Organization classification of lymphoid neoplasms. Blood. 2016;127(20):2375-90. doi: 10.1182/blood-2016-01-643569. [PubMed: 26980727]. [PubMed Central: PMC4874220].

21. Rodriguez J, Gutierrez A, Martinez-Delgado B, Perez-Manga G. Current and future aggressive peripheral T-cell lymphoma treatment paradigms, biological features and therapeutic molecular targets. Crit Rev Oncol Hematol. 2009;71(3):181-98. doi: 10.1016/j.critrevonc.2008.10.011. [PubMed: 19056295].

22. Gambacorti Passerini C, Farina F, Stasia A, Redaelli S, Ceccon M, Mologni L, et al. Crizotinib in advanced, chemoresistant anaplastic lymphoma kinase-positive lymphoma patients. J Natl Cancer Inst. 2014;106(2):djt378. doi: 10.1093/jnci/djt378. [PubMed: 24491302].

23. Savage KJ, Harris NL, Vose JM, Ullrich F, Jaffe ES, Connors JM, et al. ALK- anaplastic large-cell lymphoma is clinically and immunophenotypically different from both ALK+ ALCL and peripheral T-cell lymphoma, not otherwise specified: Report from the International Peripheral T-Cell Lymphoma Project. Blood. 2008;111(12):5496-504. doi: 10.1182/blood-2008-01-134270. [PubMed: 18385450].

24. Piva R, Agnelli L, Pellegrino E, Todoerti K, Grosso V, Tamagno I, et al. Gene expression profiling uncovers molecular classifiers for the recognition of anaplastic large-cell lymphoma within peripheral T-cell neoplasms. J Clin Oncol. 2010;28(9):1583-90. doi: 10.1200/JCO.2008.20.9759. [PubMed: 20159827].

25. Tilly H, Gaulard P, Lepage E, Dumontet C, Diebold J, Plantier I, et al. Primary anaplastic large-cell lymphoma in adults: Clinical presentation, immunophenotype, and outcome. Blood. 1997;90(9):3727-34. [PubMed: 9345059]. 